\title{
FIELD EFFICACY OF ENTOMOPATHOGENIC NEMATODES AND EGG WASPS FOR BIOCONTROL OF TOMATO FRUIT WORM, Helicoverpa zea, IN EGYPT \\ Atwa, A. A.
}

Department of Vegetable, Medicinal and Aromatic Plant Pests, Plant Protection Research Institute (PPRI), Agriculture Research Center (ARC), Ministry of Agriculture, 7 Nady Alsad Street, Dokki, Giza, Egypt

\begin{abstract}
The potential of entomopathogenic nematodes (EPNs) and an egg parasitoid for biological control of the tomato fruit worm, Helicoverpa (= Heliothis) zea (Boddie) was evaluated under field conditions for three successive seasons (2005-2007). The EPNs, all strain of Steinernema carpocapsae (Weiser) (SC), the "HP88" strain of Heterorhabiditis bacteriophora Poinar (HB) and the egg wasp Trichogramma evanescens (Westwood) (TE) were applied to control H. zea on tomato field. Three releases of each biological control agent were conducted at 10-day intervals, 15 days after tomato plants reach $30-50 \%$ effloresce. Fruit damage on untreated plots (control) was compared with plots treated by TE, SC or HB. Percentage of fruit damage was significantly reduced in all treatments when compared with untreated plants. However, the mean percentage fruit damage was significantly lower in TE-release plots when compared with plots treated with SC or HB. The obtained results suggest that using EPNs or egg wasps is a promising strategy to manage $H$. zea in tomato fields. SC nematode was more potent in decreasing the fruit damage than $\mathrm{HB}$ nematode. However, TE seems to be a potential biocontrol agent for the tomato fruit worm.

Keywords: Tomato, Helicoverpa zea, Trichogramma evanescens, Steinernema carpocapsae, Hetrorhabiditis bacteriophora, fruit damage.
\end{abstract}

\section{INTRODUCTION}

The tomato fruit worm, Helicoverpa (= Heliothis) zea (Boddie) is one of the most devastating pests of agriculture in Egypt, attacking wide range of cash and subsistence crops. It is a serious pest of cotton, corn and tomatoes (Luttrel, 1994) as its several common names indicate (e.g., bollworm, corn earworm, tomato fruit worm). It is also injurious to beans, cabbage, lettuce, pepper, alfalfa, clover, vetch, tobacco and other cultivated crops. The moths emerge during the spring and early summer and, after mating, deposit their eggs singly at dusk on the plants on which the larvae are to feed. Each moth lays from 500 to 3000 eggs, averaging about 1000, which hatch in 2 to 11 days. The larvae feed for 14 to 28 days after which they burrow into the soil and pupate (Metcalf et al., 1962). When $H$. zea infest tomato, larvae may feed on foliage and burrow in the stem, but most feeding occurs on fruits. Larvae commonly begin to burrow into fruits, feed only for a short time and then move on to attack another fruits. Tomato is more susceptible to injury when corn is not silking. In the presence of corn, moths will preferentially oviposit on fresh corn silk.

Control of the tomato fruit worm is usually achieved by application of insecticides. In general, the use of insecticides and other chemical treatments 
Atwa, A. A.

implies the risk of adverse ecological, toxicological and economic effects. Alternative techniques - mainly biological - include the use of entomopathogenic nematodes and insect parasitoids. Today, Trichogramma species (Hym.; Trichogrammatidae) are the most widely used insect natural enemy in the world ( $\mathrm{Li}, 1994)$. The Trichogramma genus includes about 180 species of minute egg parasitoids of numerous insects, especially Lepidoptera (Pintureau, 1990).

The use of polyphagous egg parasitoids of the genus Trichogramma for the control of various moth species of orchard and field crops has received much attention (Parker and Pinnell, 1972; Ridgway and Vinson, 1977). Very large numbers of Trichogramma adults are required for inundative releases to suppress established populations of moths in field crops of orchards. The egg parasitoid, Trichogramma evanescens Westwood is extensively used in inundative releases against a number of lepidopterous pests in Europe (Tran and Hassan, 1986).

Entomopathogenic nematodes in the genera Steinernema and Heterorhabditis are obligate parasites of insects (Poinar, 1990; Grewal et al., 2005). These nematodes have a mutualistic symbiosis with a bacterium (Xenorhabdus spp. and Photorhabdus spp. for steinernematids and heterorhabditids, respectively) (Poinar, 1990). Infective juveniles (IJs), the only free-living stage, enter hosts through natural openings (mouth, anus and spiracles), or in some cases, through the cuticle. After entering the host's hemocoel, nematodes release their bacterial symbionts, which are primarily responsible for killing the host within 24-48 $\mathrm{h}$, defending against secondary invaders and providing the nematodes with nutrition (Dowds and Peters, 2002). The nematodes molt and complete up to three generations within the host after which IJs exit the cadaver to search for new hosts (Kaya and Gaugler, 1993). Entomopathogenic nematodes are used to control a variety of economically important insect pests such as the black vine weevil, Otiorhynchus sulcatus (F.), diaprepres root weevil, Diaprepes abbreviates (L.), fungus gnats (Diptera; Sciaridae), various white grubs (Coleoptera; Scarabaeidae) (Klein, 1990; Shapiro-llan et al., 2002; Atwa, 2003; Grewal et al., 2005) and some lepidopterous insects (Atwa, 1999).

The use of entomopathogenic nematodes (S. carpocapsae (all strain) (Weiser) and the "HP88" strain of $H$. bacteriophora Pionar) and the commercial strain of $T$. evanescens (TE) as biological control agents for suppression of the tomato fruit worm, H. zea are being evaluated in Egypt.

\section{MATERIALS AND METHODS}

\section{Entomopathogenic nematodes preparation for field release}

Entomopathogenic nematodes (EPNs) belong to $S$. carpocapsae (all strain) and $H$. bacteriophora (HP88 strain) were cultured on the last instar larvae of Galleria mellonella (L.) according to the method of Dutky et al.(1964) and infective juveniles (IJs) were harvested from nematode traps as described by White $(1927)$ at $25 \pm 2^{\circ} \mathrm{C}$. A stock suspension of the IJs in sterilized distilled water was stored at $15^{\circ} \mathrm{C}$ until needed for field experiments. 
All nematodes were used within 2 weeks of harvest and a new infection cycle and a stock of IJs was made every 2 weeks.

\section{Trichogramma for field release}

Commercially available species of $T$. evanescens was used for field releases. The wasps were reared at the Center of Organic Agriculture in Aswan, Ministry of Agriculture and Land Reclamation, Egypt. This strain had been originally isolated from eggs of Chilo agamemnon Bles on sugar cane (Ahmed and Kira, 1960; Abbas, 1990). TE is arrhenotokous species with a female-biased sex ratio of $60-70 \%$ females (Pintureau et al., 1999). Releasing cards were prepared by gluing 3000-4000 (depending on expected sex ratio) parasitized eggs of Sitotroga cerealella on small cardboard cards $(1.5 \times 3.5 \mathrm{~cm})$. Eggs contained parasitoids of different developmental stages to ensure a staggered emergence for a continuous presence in the field.

\section{Field experiment design}

Twelve plots of tomato field plantation, each $15 \times 15 \mathrm{~m}$ of ca. 450 plants/plot were selected at El-Badrashine region, Giza Governorate. The experimental plots were grown on 30 December with GS tomato cultivar. Plots were separated from each other by $3 \mathrm{~m}$ of untreated tomato plants. Then, a randomized complete block design incorporated 3 replicates (i.e., 3 plots) for each biocontrol agent or control (untreated) was established. Tomato plants reach $30-50 \%$ effloresce by mid-March and treatments by biocontrol agents were performed on 25 March, 5 and 15 April of each season. The experiment was conducted during three consecutive growing seasons (2005-2007). Tomato plants were grown using local and commercial practices. No insecticides were applied to the field during the whole period of the present study.

On the TE release plots, an application rate of approximately 6000 female wasps per each plot was applied (about 3000 female wasps/card, 2 cards/plot) for each release for the Trichogramma. This application was repeated for three times. While the EPNs were applied with concentration of 10000 infective juveniles/plant or $20000 \mathrm{IJs} / \mathrm{m}^{2}$ (about $45 \times 10^{5} / \mathrm{plot}$ ). The application was done before sunset using 10 liters portable spraying. $50 \mathrm{ml}$ of super film was added to the nematodes suspension. This application was repeated for three times as mentioned before.

\section{Data collection}

Percentage of damaged tomato fruits by $\mathrm{H}$. zea larvae was recorded on each 15, 20, 25, 30 April and 5 May of each growing season. At each date, 10 plants were selected randomly from each plot (i.e., experimental square), 2 from each corner and 2 from the middle, to count the number of damaged tomato fruits. Then, the plants were marked to ignore them during the next inspection.

\section{Statistical analysis}

The data percentage values in this study were normalized using arcsine transformation. The significance of the mean effects was determined by analysis of variation (ANOVA). The significance of various treatments was evaluated by Duncan's multiple range test $(P<0.05)$ (SAS Institute, 1988). The mean fruit infestation was calculated and the population reduction of $H$. 
Atwa, A. A.

zea infestation was determined by using Henderson and Tilton formula (1955).

\section{RESULTS}

The tomato fruit worm, $H$. zea is highly polyphagous. The emerging caterpillars feed shortly on the leaves and flowers of tomato plants before boring into the fruit. The larva leaves the infested fruit and crawls to another several times before it completes its development. Holes with frass on the fruit's surface is a characteristic sign of the tomato fruit worm. Fruit parts fed by $H$. zea larvae are either rendered unsuitable or greatly reduced in quality and feeding often facilitates infection by pathogenic organisms. Field trials were carried out to evaluate the control efficacy by EPNs and egg wasps against the tomato fruit worm. The results of fruit damage assessments in 2005 season (Fig. 1) statistically confirmed a higher level of fruit damage on untreated (control) plants, compared with treated plants [for $\mathrm{TE}, \mathrm{F}=63.46$, d.f. $=5,12, P<0.01$ (Fig. 1-A); for $S C, F=28.78$, d.f. $=5,12, P<0.01$ (Fig. 1 $B$ ); for $\mathrm{HB}, \mathrm{F}=6.75$, d.f. $=5,12, \mathrm{P}<0.01$ (Fig. 1-C).

In the TE-release plots, the percentage of damaged fruits by $H$. zea was strongly reduced as the season goes on $(F=19.247$, d.f. $=4,10$, $\mathrm{P}<0.01$ ). Reduction rate in fruit damage reached up to $54.3,54.8,90.0,93.5$ and $95.6 \%$ on $15,20,25,30$ April and 5 May, respectively. In SC-treated plots, analysis of fruit damage data showed significant differences among inspection dates $(F=4.59$, d.f. $=4,10, P<0.05)$. Reduction rate in fruit damage recorded $47.8,55.7,74.1,71.7$ and $71.5 \%$ on $15,20,25,30$ April and 5 May, respectively. Similar trend in reduction of fruit damage was observed in HB-treated plots $(F=5.2541$, d.f. $=4,10, P<0.05)$. Reduction rate in fruit damage reached $43.7,54.3,62.8,58.1$ and $55.7 \%$ on the same dates of inspection, respectively.

During 2006, the mean percentage of fruit damage attained the same trend when TE, SC and HB were applied (Fig. 2). When the TE wasps were released, reduction in fruit damage caused by $H$. zea was significant $(F=$ 66.375 , d.f. $=5,12, \mathrm{P}<0.05$ ). Reduction rates in fruit damage reached up to $56.3,78.6,91.6,91.9$ and $96.9 \%$ on the readings of $15,20,25,30$ April and 5 May, respectively (Fig. 2-A). Applications of EPNs were less effective when compared with TE releases (Fig. 2-A,B). However, applications of SC had significant effect on larval population of $H$. zea (Fig. 2-B). Reduction rates in fruit damage reached up to $55.6,64.9,74.9,64.4$ and $70.7 \%$ during the $1^{\text {st }}-5^{\text {th }}$ readings, respectively (Fig. 2-B). Applications of HB on tomato plants were less effective when compared with SC applications. However, significant effect on the larval population of $H$. zea was recorded when HB was applied $(\mathrm{F}=66.375$, d.f. $=5,12, \mathrm{P}<0.05)$ (Fig. $2-\mathrm{C})$. Reduction rates in fruit infestation by $H$. zea recorded values of $42.3,526,64.6,51.2$ and $55.1 \%$ during the $1^{\text {st }} 5^{\text {th }}$ readings, respectively. 

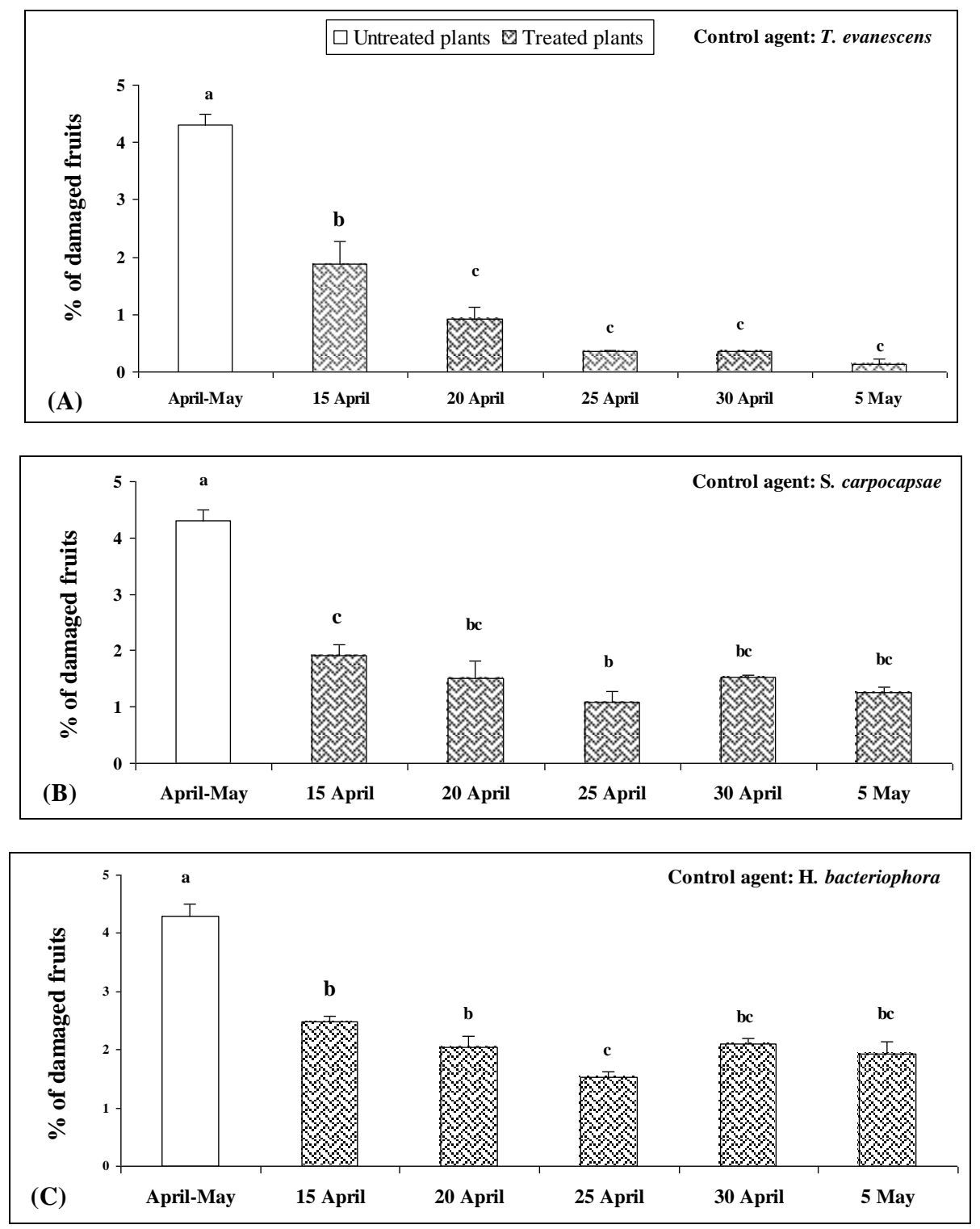

Fig. 1. Percentage of damaged (mean \pm SD) tomato fruits by $H$. zea larvae during various inspection dates of fruit maturation in treated plots by $T$. evanescens (A), $S$. carpocapsae (B) and $H$. bacteriophora (C) during 2005 growing season. Values superscripted by the same letter are not significantly different according to ANOVA, $P<0.05$ (for $A: F=63.46$, d.f. $=5$, 12; for $B: F=28.78$, d.f. $=5,12$; for $C: F=6.75$, d.f. $=5,12$ ). 
Atwa, A. A.
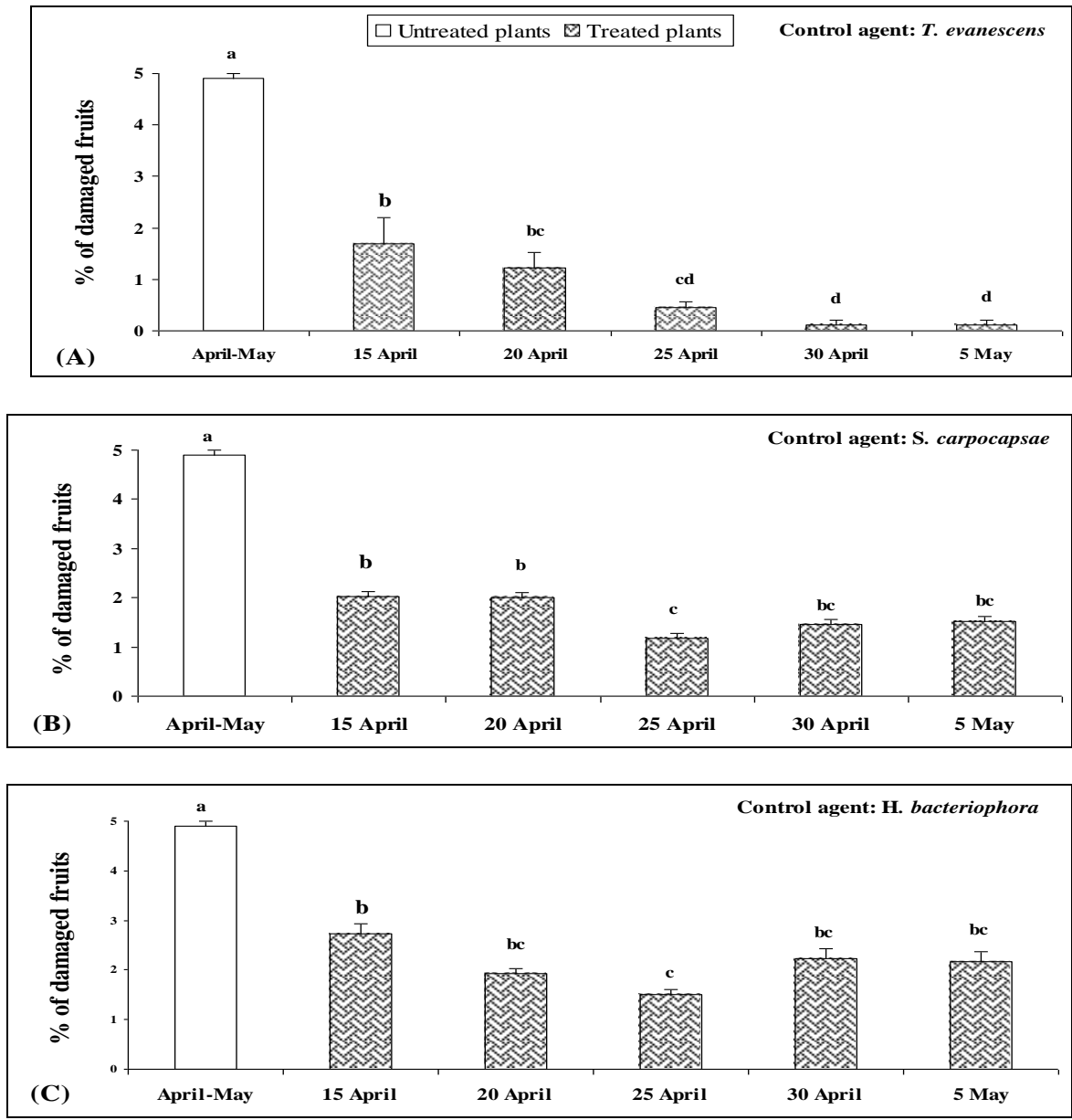

Fig. 2. Percentage of damaged (mean \pm SD) tomato fruits by $H$. zea larvae during various inspection dates of fruit maturation in treated plots by $T$. evanescens (A), S. carpocapsae (B) and $H$. bacteriophora (C) during 2006 growing season. Values superscripted by the same letter are not significantly different according to ANOVA, $P<0.05$ (for $A: F=66.375$, d.f. $=5,12$; for $B: F=2.478$, d.f. $=5,12$; for $C: F=29.34$, d.f. $=5,12$ ).

In 2007, results in Fig. 3 showed that all treatments of TE, SC and HB reduced $H$. zea infestation damage compared with untreated plants. Releasing TE wasps led to 66.3, 74.9, 90.6, 97.8 and $97.8 \%$ reduction in fruit damage in 15, 20, 25, 30 April and 5 May, respectively (Fig. 3-A). Figure 3-B showed that application of SC nematode significantly affected fruit damage by $H$. zea $(F=43.75$, d.f. $=5,12, P<0.05)$. Reduction rates in fruit damage were $58.6,5.89,75.9,70.4$ and $68.9 \%$ during the same reading dates, respectively. Changes in fruit damage by $H$. zea in plots treated by $H B$ nematodes were significant $(F=43.75$, d.f. $=5,12, P<0.05)$. During the same inspection dates, fruit damage reached 44.1, 60.6, 69.4, 54.7 and $55.91 \%$, respectively (Fig. 3-C). 
J. Agric. Sci. Mansoura Univ., 34(2), February, 2009

Fig. 3. Percentage of damaged (mean \pm SD) tomato fruits by $H$. zea larvae during various inspection dates of fruit maturation in treated plots by $T$. evanescens (A), S. carpocapsae (B) and $H$. bacteriophora (C) during 2007 growing season. Values superscripted by the same letter are not significantly different according to ANOVA, $P<0.05$ (for $A: F=29.34$, d.f. $=5$, 12; for $B$ : $F=43.57$, d.f. $=5,12$; for $C: F=28.75$, d.f. $=5,12$ ).

Figure 4 shows mean percentage of fruit damage caused by tomato fruit worm, $H$. zea, near harvest time when tomato plants were treated after 15 days of effloresce in 2005-2007 growing seasons. In 2005 season, reduction in percentage of damaged fruits was significantly different among SC, $\mathrm{HB}$ and TE treatments $(\mathrm{F}=55.081$, d.f. $=3,8, \mathrm{P}<0.01)$. Reduction rate in damaged fruits reached up to $95.4 \%$ for plants treated by TE vs. $71.2 \%$ for 
Atwa, A. A.

those treated by SC and $55.4 \%$ for plants treated by $\mathrm{HB}$. The same trend was observed during $2006(\mathrm{~F}=159.99$, d.f. $=3,8, \mathrm{P}<0.01)$ and $2007(\mathrm{~F}=$ 124.151 , d.f. $=3,8, P<0.01$ ) trials. These results further indicate that the efficacy of SC and HB nematodes differed significantly. SC nematode was more potent in decreasing the fruit damage when compared with HB one (Fig. 4-A,B). In all trials, application of TE wasps proved to be more effective than either of SC or HB nematodes.

Fig. 4. Mean percent ( \pm SD) of damaged tomato fruits by $H$. zea larvae per plant at harvest time after TE and EPNs (SC and HB) treatments. Values superscripted by the same letter are not significantly different according to ANOVA, P<0.01 (for A: $F=$ 178.851, d.f. $=3$, 8; for $B: F=159.99$, d.f. $=3$, 8; for $C: F=$ 124.151, d.f. = 3, 8). 


\section{DISCUSSION}

H. zea is fruit feeder, though fruits of crops such as tomato and cotton bolls undergo most damage. It is a multivoltive with diapause, highly fecund and capable of moving long distances as adults (Metcalf et al., 1962). Chemical control of $\mathrm{H}$. zea is very difficult because the insect has developed tolerance to many insecticides (Karim, 2000). The biological control of $H$. zea using EPNs (SC or HB) and TE wasps has proven successful as safety environmental bio-agents than conventional insecticides for controlling the tomato fruit worm. The percentages of damaged fruits after applying SC, HB or TE were all significantly less in the three successive study years than those from the control group. However, applications of TE were most effective agent and reduced fruit damage below $0.3 \%$. The outcome of TE field experiments is encouraging for an efficient use of Trichogramma spp. in controlling the $\mathrm{H}$. zea. In fact, the field release of mass-reared egg parasitoids of the genus Trichogramma could be an option (Li, 1994), but has never been properly explored.

Concerning the EPNs, the obtained results revealed appreciable field efficacy of SC against $H$. zea, resulting in more protection of tomato fruits than those from HB group. The HB was the least effective test agent. According to Choo et al.(1989) and Alatorre-Rosas and Kaya (1990), HB searches for hosts and generally infects deeper in the soil profile, whereas SC waits and infects hosts near the soil surface. High efficiency of heterorhabditid nematodes was reported against the Japanese beetle, Popillia japonica Newman (Georgis and Gaugler, 1991). In our investigation, the steinernematid nematode is so far the most promising nematode agent for further studies of controlling the underground stages of $H$. zea that pupate near the soil surface. Finally, SC seems to be a potential biocontrol nematode agent for the $H$. zea.

\section{REFERENCES}

Abbas, M.S.T. (1990). Interactions between host, egg and larval parasitoids and nuclear polyhedrosis virus. Bull. Entomol. Soc. Egypt, 16: 133-141.

Ahmed, M.K. and M.T. Kira (1960). Studies on corn borers and their control. Technical report, Cairo (in Arabic), 4: 55-72.

Alatorre-Rosas, R. and H.K. Kaya (1990). Interspecific competition between entomopathogenic nematodes in the genera Heterorhabditis and Steinernema for an insect host in sand. J. Inveretebr. Pathol., 55: 179188.

Atwa, A.A. (1999). Interaction of certain insecticides and entomopathogenic nematodes in controlling some insect pests on fruit and vegetable crops. M.Sc. Thesis, Faculty of Agriculture, Ain-Shams University, Shobra El-Khaima, Cairo, Egypt, 161 pp.

Atwa, A.A. (2003). Identification, mass culture and utilization of entomopathogenic nematodes against insect pests. Ph.D. Thesis, Faculty of Agriculture, Cairo University, Giza, Egypt, 172 pp. 
Atwa, A. A.

Choo, H.Y.; H.K. Kaya; T.M. Burlando and R. Gaugler (1989). Entomopathogenic nematodes: host-finding ability in the presence of plant roots. Environ. Entomol., 18: 1136-1140.

Dowds, B.C.A. and A. Peters (2002). Virulence mechanisms. In: Gaugler, R. (Ed.), Entomopathogenic Nematology. CABI, New York, NY, pp. 79-98.

Dutky, S.R.; J.V. Thompson and G.E. Cantwell (1964). A technique for the mass propagation of the DD-136 nematode. J. Insect Pathol., 6: 417422.

Georgis, R. and R. Gaugler (1991). Predictability in biological control using entomopathogenic nematodes. J. Econ. Entomol., 84: 713-720.

Grewal, P.S.; R.U. Ehlers and D.I. Shapiro-llan (2005). Critical issues and research needs for expanding the use of nematodes in biocontrol. In: Grewal, P.S., Ehlers, R.U., Shapiro-llan, D.I. (Eds.), Nematodes as Biocontrol Agents. CABI, New York, NY, pp. 479-489.

Henderson, C.F. and W. Tilton (1955). Tests with acaricides against the brown wheat mite. J. Econ. Entomol., 48: 157-161.

Karim, S. (2000). Management of Helicoverpa armigera: A Review and Prospectus for Pakistan. Pakistan J. Biol Sci., 3: 1213-1222.

Kaya, H.K. and R. Gaugler (1993). Entomopathogenic nematodes. Annual Review of Entomology, 38: 181-206.

Klein, M.G. (1990). Efficacy against soil-inhabiting insect pests. In: Gaugler, R., Kaya, H.K. (Eds.), Entomopathogenic Nematodes in Biological Control. CRC Press, Boca Raton, FL, pp. 195-214.

$\mathrm{Li}$, L.Y. (1994). Worldwide use of Trichogramma for biological control on different crops. A Survey. In: Wajnberg,E., Hassan,S.A. (Eds.) Biological Control with Egg Parasitoids. CAB International, Oxon, pp. 37-51.

Luttrell, R.G. (1994). Cotton pest management. 2: A U.A. Perspective. Annu. Rev. Entomol., 39: 527.

Metcalf, C.L.; W.P. Flint and R.L. Metcalf (1962). Destructive and useful insects. Ed. e, $1087 \mathrm{pp}, \mathrm{NY}$.

Parker, F.D. and R.E. Pinnell (1972). Effectiveness of Trichogramma spp. in parasitizing eggs of Pieris rapae and Trichoplusi ni. 1. Field studies. Environ. Entomol., 1: 785-789.

Pintureau, B. (1990). Polymorphisme, biogeography et specificite parasitaire des Trichogramma europeens (Hym.: Trichogrammatidae). Bull. Soc. Entomol. Fr., 95: 17-38.

Pintureau, B.; L. Chapelle and B. Delobel (1999). Effects of repeated thermic and antibiotic treatments on Trichogramma (Hym.; Trichogrammatidae) symbiont. J. Appl. Entomol., 123: 473-483.

Poinar Jr., G.O. (1990). Biology and taxonomy of Steinernematidae and Heterorhabditidae. In: Gaugler, R., Kaya, H.K. (Eds.), Entomopathogenic Nematodes in Biological Control. CRC Press, Boca Raton, FL, pp. 23-62.

Ridgway, R.L. and S.B. Vinson (eds.) (1977). Biological Control by Augmentation of Natural Enemies. Plenum Press, New York, 480 pp.

SAS Institute (1988). "SAS User's Guide: Statistics". SAS Inst., Cary, NC. 
Shapiro-Ilan, D.I.; D.H. Gouge and A.M. Koppenhfer (2002). Factors affecting commercial success: case studies in cotton, turf and citrus. In: Gaugler, R. (Ed.), Entomopathogenic Nematology. CABI, New York, NY, pp. 333-356.

Tran, L.C. and S.A. Hassan (1986). Preliminary results on the utilization of Trichogramma evanescens West. to control the Asian corn borer. J. Appl. Entomol., 101: 11, 18-23.

White, C.F. (1927). A method for obtaining infective larvae from culture. Science, 66: 302-303.

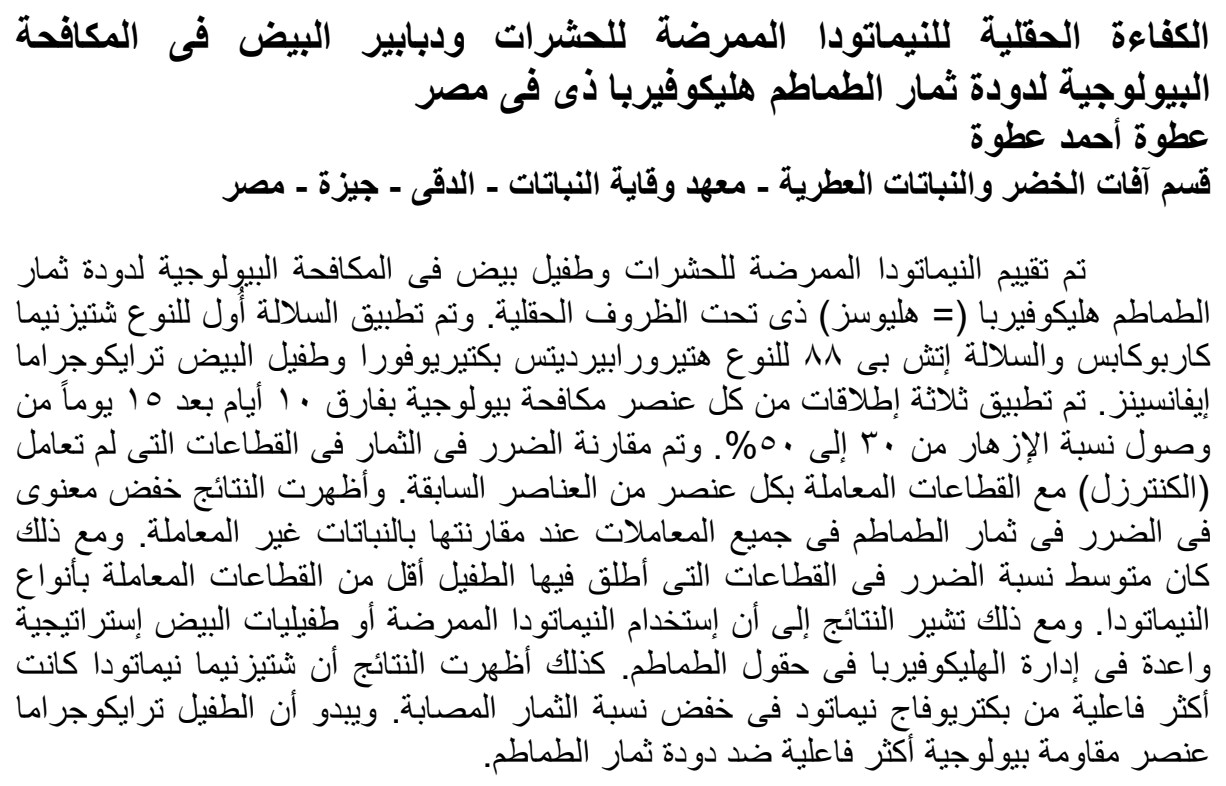

